\title{
Investment Valuation with Tax-optimized Financing Decisions and a Tax-optimized Default Alternative
}

\author{
Jochen Hundsdoerfer, Institute of Auditing and Business Taxation, Freie Universität Berlin, Email: LS-Hundsdoerfer@wiwiss.fu-berlin.de \\ Lutz Kruschwitz, Department of Banking and Finance, Freie Universität Berlin, Email: LK@wacc.de \\ Daniela Lorenz, Department of Banking and Finance, Freie Universität Berlin, Email: daniela.lorenz@gmx.net*
}

\begin{abstract}
In this paper we evaluate an indivisible investment project that is carried out in a corporation under very simple premises. In particular, we discuss a one-period model with certainty, the pure domestic case and proportional tax rates. Surprisingly, the decision problem turns out to be rather complex if one has to make allowance for different taxation of the corporation and its owner. Altogether there are more than 10 cases that have to be distinguished if the firm's managers want to make a correct decision, depending on the relation of personal and corporate tax rates.
\end{abstract}

Keywords: Investment Decisions, Financing Policy, Payout Policy, Dividend Distribution Decisions, Tax Planning

\section{Problem}

For a long time business studies have dealt with the evaluation of taxable investments under the assumption of certainty. The same is true for optimal financing regarding taxation. However, the taxation consequences of different ways to finance an investment are rarely considered when valuing investments. ${ }^{1}$ This is especially important if the investment is carried out by a corporation subject to tax. The taxation of corporations as well as their shareholders may cause distortions. In the literature, the tax effects on investment decisions, ${ }^{2}$ on capital structure decisions, ${ }^{3}$ and on dividend distributions ${ }^{4}$ are discussed separately. There is no closed model with simultaneous aftertax optimization of the default alternative for the

\footnotetext{
Thanks are due to Rainer Niemann, the department editor of this issue, and two anonymous referees for suggestions for the improvement of this paper. Special thanks go to Dominica Canefield, Sven Husmann, Olaf Siegmund, Christian Sielaff, and Caren Sureth for their helpful comments and remarks on earlier versions. Remaining deficiencies are the authors' alone.

1 See Husmann and Kruschwitz (2001), Husmann and Kruschwitz (2002), Kiesewetter and Dietrich (2007), Husmann (2007).

2 E.g., Hassett and Hubbard (2002).

3 E.g., Kaplow (2006), pp. 28-33; Graham (2006), pp. 576583.

4 E.g., Auerbach (2002).
}

shareholder relief system. ${ }^{5}$ We are going to close this gap with this study.

It will be examined whether it is worth carrying out investment projects. This will be analyzed in a model with only two payment date points $(t=0$ and $t=1)$. Regarding certainty it is assumed that the investor owns a corporation subject to tax and that a shareholder relief system is applied. ${ }^{6}$ It is evaluated whether the investment is to be preferred over its default alternative, measured by the financial resources which are available at the end of the planning period (terminal value). It is assumed that the investor is unsatiated.

A model with only one investment and one return cash flow date in which all data are assumed as certain is not suitable for practical decisions. The function of the model is rather to evaluate tax effects on the investor's objective (here, the terminal value) in an extremely simplified and stylized decision situation. In particular, it will be shown how the additional terminal value contribution of the investment project reacts to changes in the firm's tax rate.

\footnotetext{
5 This is made obvious by e.g Haase and Diller (2002).

6 Similar to Husmann and Kruschwitz (2001), Husmann and Kruschwitz (2002).
} 


\section{Model}

\subsection{Assumptions}

The assumptions that affect the financing of the investment project are critical for our model. At the date $t=0$ the firm - a corporation subject to corporate taxation - possesses cash in the amount of $C_{0}$ which is covered by revenue reserves that have already been taxed. In addition, the owner of the firm has personal cash resources in the amount of $P_{0}$. It is assumed that the owner has already satisfied his or her own current consumption needs. In order to realize the indivisible investment, the firm must raise the amount of $I_{0}$. If the existing resources $C_{0}$ are insufficient or it is advantageous to allocate these resources to another use, the firm can acquire funds from two financing resources: Either the owner transfers personal resources to the firm (external financing with equity), or the firm takes out a loan (external financing with credit capital). ${ }^{7}$ At the date $t=1$, a complete refund and repayment of the corresponding amounts is made to the financiers. If the firm decides against the investment project, the project does not require the whole amount of available capital, or it is financed externally. The firm can either distribute the remaining resources to the owner (i.e., declare a dividend) or reinvest them in the capital market. We exclude both capital reductions that exceed the increase in capital at the date $t=0$ and share repurchases. If the firm takes out a loan, the creditor can demand an interest rate based on the market interest rate $i$. The same interest rate applies if the firm or owner makes an investment. We exclude personal debts.

The firm pays corporate income tax. Paid interest may be fully or partially deductible. Personal interest income is completely subject to income tax. Dividends are taxed according to the shareholder relief system.

Each evaluation of an investment project is relative because it is always based on a comparison with a default alternative. If a complete capital market is assumed and taxes are not considered, it is sufficient to characterize the default alternative as

\footnotetext{
7 The consideration of credit financing by the owner is not necessary in our model for the following reason. If there is a single market rate of interest and if it is assumed that the external creditor borrows the amount from the owner, external financing with credit is as good as credit financing by the owner. See Gratz (2002), p. 491, where it is also considered that private yields on interest are not completely taxed.
}

a financial investment and/or a credit with the interest rate $i$. If profit taxes are considered, a higher degree of precision is necessary because the terminal value for the owner will vary according to whether a capital investment is made by the firm or the owner himself. In order to avoid the investment project being compared with a suboptimal alternative, the default alternative itself must also be optimized regarding taxes.

\subsection{Relevant payments and budget restrictions}

Table 1 shows a complete overview of all payments that are incurred by the firm and the owner. In order to avoid overlap work, we will include the investment project. If this project is not carried out, the corresponding payments $I_{0}$ and $C F_{1}$ are nullified. The symbols in Table 1 are mostly selfexplanatory: Cash inflows have a positive algebraic sign; cash outflows have a negative algebraic sign. The dividend distribution at the date $t=1$ is the cash flow of the investment project $C F_{1}$ plus the inflow from the financial investment $M_{0}^{c}(1+i)$ minus the cash outflow to the creditor $D_{0}(1+i)$ minus the equity repayment to the owner $E_{0}$ minus the tax payment of the firm $T_{1}^{c}$ :

$$
D i v_{1}=C F_{1}+M_{0}^{c}(1+i)-E_{0}-D_{0}(1+i)-T_{1}^{c} .
$$

Table 1: Overview of all payments including the investment project

\begin{tabular}{lrr} 
Corporate level & $\boldsymbol{t}=\mathbf{0}$ & $\boldsymbol{t}=\mathbf{1}$ \\
\hline Available cash resources & $C_{0}$ & - \\
\hline Investment project & $-I_{0}$ & $+C F_{1}$ \\
\hline $\begin{array}{l}\text { External financing } \\
\text { with equity }\end{array}$ & $+E_{0}$ & $-E_{0}$ \\
\hline $\begin{array}{l}\text { External financing } \\
\text { with credit }\end{array}$ & $+D_{0}$ & $-D_{0}(1+i)$ \\
\hline Financial investment & $-M_{0}^{c}$ & $+M_{0}^{c}(1+i)$ \\
\hline Taxes & $-T_{0}^{c}$ & $-T_{1}^{c}$ \\
\hline Dividends & $-D i v_{0}$ & $-D i v_{1}$ \\
\hline Sum & $\mathbf{0}$ & $\mathbf{0}$ \\
\hline Personal level & $\boldsymbol{t}=\mathbf{0}$ & $\boldsymbol{t}=\mathbf{1}$ \\
\hline Available cash resources & $P_{0}$ & - \\
\hline Equity deposit & $-E_{0}$ & $+E_{0}$ \\
\hline Financial investment & $-M_{0}^{p}$ & $+M_{0}^{p}(1+i)$ \\
\hline Taxes & $-T_{0}^{p}$ & $-T_{1}^{p}$ \\
Dividends & $+D i v_{0}$ & $+D i v_{1}$ \\
\hline Sum & $\mathbf{0}$ & $=\boldsymbol{V}_{\mathbf{1}}$ \\
\hline
\end{tabular}


Using (1), the terminal value for the owner is described by the following equation:

$$
\begin{aligned}
V_{1}= & E_{0}+M_{0}^{p}(1+i)-T_{1}^{p}+D i v_{1} \\
= & C F_{1}+\left(M_{0}^{c}+M_{0}^{p}-D_{0}\right)(1+i) \\
& -T_{1}^{c}-T_{1}^{p} .
\end{aligned}
$$

Table 1 contains a budget restriction at the date $t=0$ for the firm:

$$
I_{0}+M_{0}^{c}+\operatorname{Div}_{0}=C_{0}+D_{0}+E_{0}-T_{0}^{c} .
$$

The budget restriction for the owner at $t=0$ is

（4） $\quad E_{0}+M_{0}^{p}+T_{0}^{p}=P_{0}+\operatorname{Div}_{0}$.

$\operatorname{Div}_{0}, E_{0}, D_{0}, M_{0}^{p}$ and $M_{0}^{c}$ are not supposed to become negative. Capital reduction and loan repayments at $t=0$ are hereby excluded.

\subsection{Corporate taxes and personal taxes}

In general we assume that all tax rates are proportional and constant over time. As a corporation, the firm pays profit taxes on its profits with the rate $\tau_{c}$. If more than one profit tax is levied, $\tau_{c}$ is a tax multifactor that contains every profit tax. Many countries do not allow a full charge of debit interest in calculating the tax base of every profit tax. So we define a second tax multifactor $\tau_{i}$ to model the additional tax on debit interest. We call this rate "the debit interest surcharge rate".

Fiscal law may allow for part of the investment payment to be already charged at date $t=0$ as costs, for instance purchase or production costs of the investment payment, or partial "immediate amortization". Since on the date $t=0$ no sales have yet been realized, the firm will report a taxable loss. If the immediately deductible part of the investment payment is called $\beta$, the following corporate tax equation results:

（5） $T_{0}^{c}=-\tau_{c} \beta I_{0}$.

Therefore, the firm receives a tax refund if we assume that an immediate and complete loss adjustment is possible.

We assume that the profit contribution of the investment project in $t=1$ amounts to $C F_{1}-(1-\beta) I_{0}$ (clean surplus concept) and that the profits are completely domestic. To calculate the corporate tax base, the interest income of the financial investment must be added and the paid interest for the credit must be charged. The tax base of the debit interest surcharge is $i D_{0}$. Now the tax equation of the firm for $t=1$ is applied as follows:

(6) $T_{1}^{c}=\tau_{c}\left(C F_{1}-(1-\beta) I_{0}+i\left(M_{0}^{c}-D_{0}\right)\right)+\tau_{i} i D_{0}$.

The owner must pay income tax in $t=0$ in the amount of

(7) $T_{0}^{p}=\tau_{p} \delta \operatorname{Div}_{0}$,

(shareholder relief system) where $\tau_{p}$ represents the income tax rate and $\delta \in(0,1]$ represents the taxable part of the dividend. In $t=1$ the owner receives a dividend from the firm which is also taxable under the shareholder relief system. Additionally, the owner gains personal interest that is taxed in full. The income tax at $t=1$ is

(8) $T_{1}^{p}=\tau_{p} \delta D i v_{1}+\tau_{p} i M_{0}^{p}$.

A definitive flat rate withholding tax on interest and dividends can be easily integrated by the right choice of $\tau_{p}$ and $\delta .^{8}$

\subsection{General description of the terminal value}

In order to analyze the terminal value for the owner in detail, we start with equation (2). Solving equations (3) and (4) for $M_{0}^{c}$ and/or $M_{0}^{p}$ and insertion results in the following:

$$
\begin{aligned}
V_{1}= & C F_{1}+\left(P_{0}+C_{0}-I_{0}-T_{0}^{c}-T_{0}^{p}\right)(1+i) \\
& -T_{1}^{p}-T_{1}^{c} .
\end{aligned}
$$

Including the tax equations (5), (6), (7) and (8), using equation (1) and repeated use of equations (3) and (4) results in

$$
\begin{aligned}
& \text { (9) } V_{1}=\underbrace{\left(-I_{0}\left(1+i\left(1-\beta \tau_{c}\right)\right)+C F_{1}\right)\left(1-\tau_{c}\right)\left(1-\delta \tau_{p}\right)}_{\text {Contribution of the investment project }} \\
& +\underbrace{P_{0}\left(1+i\left(1-\tau_{p}\right)\right)+C_{0}\left(1+i\left(1-\tau_{c}\right)\right)\left(1-\delta \tau_{p}\right)}_{\text {Contribution of the transfer-free financial investment }}
\end{aligned}
$$

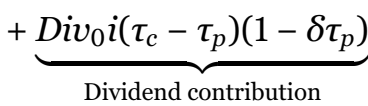

$$
\begin{aligned}
& \text { - } \underbrace{E_{0} i\left(\tau_{c}-\tau_{c^{*}}\right)\left(1-\delta \tau_{p}\right)}_{\text {Contribution of external equity financing }} \\
& -\underbrace{\alpha D_{0} i \tau_{i}\left(1-\delta \tau_{p}\right)}_{\text {Credit contribution }} \text {. }
\end{aligned}
$$

8 The effect of a flat rate withholding tax on investment and financing decisions is discussed in detail by Kiesewetter and Lachmund (2004). 
$\tau_{c^{*}}$ stands for

(10) $\tau_{c^{*}}=\frac{(1-\delta) \tau_{p}}{1-\delta \tau_{p}}$

Disregarding local business tax and interest effects, $\tau_{c^{*}}$ can be interpreted as the corporate income tax rate for which distributed profits in the shareholder relief system are subject to the same tax burden as earnings of the owner subject to income tax. ${ }^{9}$ Equation (9) is central to all further considerations. It shows that the terminal value of the owner consists of five sources:

1. Contribution of the investment project to the terminal value: If the project is not carried out $\left(I_{0}=0\right.$ and $\left.C F_{1}=0\right)$, this component will disappear.

2. Contribution to the terminal value in cases of financial investments free from transfers: The second component describes which contribution results from a complete financial investment of all available personal and corporate financial resources for the terminal value. We call this "financial investments free from transfers" because in this case the firm invests amount $C_{0}$ and the owner invests amount $P_{0}$ at the interest rate $i$. In $t=0$, any transfer of financial resources between the firm and the owner that might be necessary for financing the project or for tax planning is not part of this component.

3. Dividend contribution: The third component describes how the transfer (distribution) of financial resources in $t=0$ from the firm to the owner contributes to the terminal value. This contribution is obviously positive if $\tau_{c}>\tau_{p}$, which means that the profit tax rate of the firm is higher than the income tax rate of the owner.

4. Contribution of external equity financing: The contribution of a capital increase describes the influence of a transfer of the owner's personal available financial resources to the firm (temporary increase in capital). The contribution of a capital increase is positive if $\tau_{c}<\tau_{c^{*}}$.

5. Credit contribution: The admittance of a credit by the firm and its effects on the terminal value

9 For example, when $\tau_{p}=0.4$ and $\delta=0.5, \tau_{c}$. results in 0.25 . of the owner are included by the credit contribution. This component has a negative influence on the terminal value providing a positive tax rate $\tau_{i}$ below $100 \%$. Nevertheless, it cannot be concluded that external financing must in each case be avoided. It is possible that the net benefits from a (complete or partial) credit-financed investment project exceed the net benefits from the no-credit case.

For the following it will be useful to prove that $0 \leq \tau_{c^{*}}<\tau_{p}$ holds. For $\tau_{p} \in(0,1)$ and $\delta \in(0,1]$ the following is applied:

$$
\begin{aligned}
& \tau_{c^{*}} \geq 0 \\
& \frac{(1-\delta) \tau_{p}}{1-\delta \tau_{p}} \geq 0 .
\end{aligned}
$$

As the denominator is positive, we receive

$$
(1-\delta) \tau_{p} \geq 0
$$

which is obviously correct. In order to show that $\tau_{c^{*}}<\tau_{p}$ is applied, we insert equation (10) and receive the following:

$$
\frac{(1-\delta) \tau_{p}}{1-\delta \tau_{p}}<\tau_{p}
$$

Since $\tau_{p}$ and $\delta$ are positive, we are able to determine that

$$
\begin{aligned}
1-\delta & <1-\delta \tau_{p} \\
\delta & >\delta \tau_{p} \\
1 & >\tau_{p}
\end{aligned}
$$

remains. This is what we had presumed.

\section{Tax-optimized default alternative}

We focus on the default alternative so that $I_{0}=0$ and $C F_{1}=0$. Div $v_{0}, E_{0}$ and $D_{0}$ remain as decision variables. If we use the symbol $\underline{V}_{1}$ which stands for the terminal value reached with the help of the default alternative, we receive the terminal value equation (9) with the corresponding reduction

$$
\begin{aligned}
\underline{V}_{1}= & P_{0}\left(1+i\left(1-\tau_{p}\right)\right) \\
& +C_{0}\left(1+i\left(1-\tau_{c}\right)\right)\left(1-\delta \tau_{p}\right) \\
& +\operatorname{Div}_{0} i\left(\tau_{c}-\tau_{p}\right)\left(1-\delta \tau_{p}\right) \\
& -E_{0} i\left(\tau_{c}-\tau_{c^{*}}\right)\left(1-\delta \tau_{p}\right) \\
& -D_{0} i \tau_{i}\left(1-\delta \tau_{p}\right) .
\end{aligned}
$$


In the first step we will show under what set of tax rates a dividend $\left(D_{i v_{0}}\right)$, an increase in capital $\left(E_{0}\right)$ or a credit $\left(D_{0}\right)$ is beneficial. In the second step we deduce for each tax rate combination a ranking of the above-mentioned alternatives. Due to $\delta \in(0,1]$ as well as $\tau_{p} \in(0,1)$, the following conclusions can be drawn:

1. If permanent debt interest is not completely deductible $\left(\tau_{i}>0\right)$, the contribution of credit financing to the terminal value of the owner is always negative. ${ }^{10}$ Credit capital should not be acquired. Otherwise, $\left(\tau_{i}=0\right)$ it makes no difference whether or not a loan is taken.

2. If $\tau_{c}>\tau_{p}$, each dividend payment increases the terminal value of the owner in $t=0$. The budget restriction of the firm according to equation (3) must be considered. The income tax on dividends according to the shareholder relief system is irrelevant to this decision because the tax is due in any case, either immediately in $t=0$ or on reserves which are increased by interest in $t=1$. The only factor of importance is how the interest incomes are taxed. If the interest incomes are obtained privately (dividend distribution in $t=0$ ), the complete income tax rate $\tau_{p}$ is applied to the interest. Otherwise, the profit tax rate of the firm $\tau_{c}$ is applied. ${ }^{11}$

3. The contribution of a capital increase is positive if $\tau_{c}<\tau_{c^{*}}$. Considering the budget restriction of the owner according to equation (4), external financing with equity by a temporary increase in capital should be selected in order to maximize the firm's financial investment.

Above, we proved that $\tau_{c^{*}}<\tau_{p}$ if $\tau_{p}<1$. However, it is possible that $\tau_{c^{*}}<\tau_{c}<\tau_{p}$ where, at the date $t=0$, neither the payment of the dividend nor a temporary increase in capital is advantageous. Under these circumstances the optimal strategy would be for the firm to invest $C_{0}$ and the owner to invest $P_{0}$ in the capital market ("free-of-transfer financial investment"). It is impossible to increase the terminal value by maximizing the personal financial investment with dividend payments or by maximizing the financial investment of the firm

\footnotetext{
${ }_{10}$ Regarding a particular case, Gratz (2002), p. 490 f., obtains the same result.

11 See Elser (2001), p. 807 f.; Hundsdoerfer (2001), p. 116 f. Similar results are obtained by Schreiber and Rogall (2000), p. $724 \mathrm{f}$.
}

with a temporary increase in capital. That is remarkable.

Now we will look at four scenarios that can be described by a set of tax rates. For each of these scenarios, an optimal policy is determined.

\section{Scenario a: Low corporate tax rate $\left(\tau_{c} \leq \tau_{c^{*}}\right)$}

Under these circumstances it is recommended to minimize the personal financial investment and to maximize the financial investment by the firm. This means that $E_{0}=P_{0}, D i v_{0}=0$ and $D_{0}=0$. The terminal value comes to

$$
\begin{aligned}
\underline{V}_{1}^{a}= & P_{0}\left(1+i\left(1-\tau_{c}\right)\left(1-\delta \tau_{p}\right)\right) \\
& +C_{0}\left(1+i\left(1-\tau_{c}\right)\right)\left(1-\delta \tau_{p}\right) .
\end{aligned}
$$

2. Scenario $b$ : Medium corporate tax rate $\left(\tau_{c^{*}}<\tau_{c} \leq \tau_{p}\right)$

If this condition exists, neither should dividends be distributed nor should capital temporarily be increased so that $\operatorname{Div}_{0}=0, E_{0}=0$ and $D_{0}=0$. We receive

$$
\begin{aligned}
\underline{V}_{1}^{b}= & P_{0}\left(1+i\left(1-\tau_{p}\right)\right) \\
& +C_{0}\left(1+i\left(1-\tau_{c}\right)\right)\left(1-\delta \tau_{p}\right) .
\end{aligned}
$$

3. Scenario c: High corporate tax rate $\left(\tau_{p}<\tau_{c} \leq \tau_{p}+\tau_{i}\right)$

In this scenario the optimal strategy is to transfer all existing resources of the firm immediately to private property by choosing $D i v_{0}=$ $C_{0}, E_{0}=0$ and $D_{0}=0$. Then the terminal value is

$$
\begin{aligned}
\underline{V}_{1}^{c}= & P_{0}\left(1+i\left(1-\tau_{p}\right)\right) \\
& +C_{0}\left(1+i\left(1-\tau_{p}\right)\right)\left(1-\delta \tau_{p}\right) .
\end{aligned}
$$

4. Scenario d: Very high corporate tax rate $\left(\tau_{p}+\tau_{i}<\tau_{c}\right)$

In this case it is also optimal to transfer all existing resources to private property. In a world where taxes do not matter, the terminal value of the owner cannot be increased by credit financing of the firm in $t=0$ and at the same time distributing the loan value as a dividend. The interest paid by the firm would equate to the interest income obtainable at the personal level. When considering taxes, this irrelevance disappears. Equation (9) shows that it is worth having a credit-financed dividend if

$$
\operatorname{Div}_{0} i\left(\tau_{c}-\tau_{p}\right)\left(1-\delta \tau_{p}\right)-D_{0} i \tau_{i}\left(1-\delta \tau_{p}\right)>0
$$


holds. If a corresponding credit amount is distributed completely $\left(D_{0}=D i v_{0}\right)$, this relation is fulfilled if $\tau_{p}+\tau_{i}<\tau_{c}$. In our model, unlimited economic prosperity could be achieved by a credit-financed immediate dividend. However, there are distribution restrictions ${ }^{12}$ which should be built into the model. The dividends must not exceed the distributable revenue reserves $D i v_{0}^{\max }$ so that $\operatorname{Div}_{0} \leq D i v_{0}^{\max }$. To simplify, we assume in the following that the firm's resources $C_{0}$ can be fully distributed $\left(D i v_{0}^{\max } \geq C_{0}\right.$ ). So, in scenario d Div $v_{0}^{\max }$ is distributed. If $C_{0}$ does not suffice to finance this dividend, the difference is financed by a loan.

How can this credit and interest be paid in $t=1$ ? Since we analyze the default alternative, there are no returns on the investment project. Nor does the firm receive returns on a financial investment in $t=1$ because it distributes every penny in $t=0$. The credit would definitely default, resulting in no creditor being found. However, as obtaining credit is advantageous for the owner, he or she will be willing to guarantee the debt with his or her personal property. For tax purposes, this guarantee systematically has to be treated as deferred acquisition costs of his investment. ${ }^{13}$ The part $\delta$ of the deferred acquisition costs saves on income tax. ${ }^{14}$ The planning horizon of our model ends at $t=1$, so tax savings must be considered at this point in time.

Therefore, there is a redemption payment by the owner on a debt of his firm, a corporation. The part $\delta$ of this payment reduces the owner's income tax burden. In our model this payment can be interpreted as a negative dividend $\left(\right.$ Div $\left._{1} \leq 0\right)$. Although dividends cannot become negative, a fictitious negative dividend would have the same payment effects and tax consequences as claiming a guarantee.

\footnotetext{
12 See, e.g., for Germany $\S 30$ para 1 GmbHG (Act Concerning Limited Liability Companies).

13 See, e.g., for Germany the Bundesfinanzhof (Federal Fiscal Court) ruling of 24.04.1997 VIII R 23/93, Bundessteuerblatt II 1999, 342; Bundesfinanzhof ruling of 06.07.1999 VIII R 9/98, Bundessteuerblatt II 1999, 817.

14 This holds, e.g., for the German shareholder relief system, providing $\S 17$ or $\S 23$ EStG (German Income Tax Act) applies. The same is true for the liquidation of the firm ( $\$ 17$ para 4 EStG).
}

Table 2:

Tax-optimized default alternative

\begin{tabular}{lcccc} 
& \multicolumn{4}{c}{ Scenario } \\
& $\mathbf{a}$ & $\mathbf{b}$ & $\mathbf{c}$ & $\mathbf{d}$ \\
\hline Range & $\tau_{c} \leq \tau_{c^{*}}$ & $\tau_{c^{*}}<\tau_{c} \leq \tau_{p}$ & $\tau_{p}<\tau_{c} \leq \tau_{p}+\tau_{i}$ & $\tau_{p}+\tau_{i}<\tau_{c}$ \\
\hline Div 0 & 0 & 0 & $C_{0}$ & $D i v_{0}^{\max }$ \\
\hline$E_{0}$ & $P_{0}$ & 0 & 0 & 0 \\
\hline$D_{0}$ & 0 & 0 & 0 & Div $_{0}^{\max }-C_{0}$ \\
\hline
\end{tabular}

Table 1 shows the following budget restriction for the firm in $t=1$ :

$$
C F_{1}+M_{0}^{c}(1+i)=D_{0}(1+i)+E_{0}+T_{1}^{c}+D i v_{1} .
$$

As $C F_{1}=0, M_{0}^{c}=0$ and $E_{0}=0$, the negative dividend (the owner claims the guarantee) equals the amount of the loan plus interest minus tax savings on the interest $\left(-T_{1}^{c} \geq 0\right)$ in $t=0$ :

$$
D i v_{1}=-D_{0}(1+i)-T_{1}^{c} .
$$

Considering the credit-financed dividend in $t=0$, the terminal value for $D i v_{0}=D i v_{0}^{\max }$, $E_{0}=0$ and $D_{0}=D i v_{0}^{\max }-C_{0}$ comes to

$$
\begin{aligned}
\underline{V}_{1}^{d}= & P_{0}\left(1+i\left(1-\tau_{p}\right)\right) \\
& +C_{0}\left(1+i\left(1-\tau_{c}\right)\right)\left(1-\delta \tau_{p}\right) \\
& +D i v_{0}^{\max } i\left(\tau_{c}-\tau_{p}\right)\left(1-\delta \tau_{p}\right) \\
& -\left(D i v_{0}^{\max }-C_{0}\right) i \tau_{i}\left(1-\delta \tau_{p}\right) \\
= & P_{0}\left(1+i\left(1-\tau_{p}\right)\right) \\
& +C_{0}\left(1+i\left(1-\tau_{c}+\tau_{i}\right)\right)\left(1-\delta \tau_{p}\right) \\
& +D i v_{0}^{\max } i\left(\tau_{c}-\tau_{p}-\tau_{i}\right)\left(1-\delta \tau_{p}\right) .
\end{aligned}
$$

Table 2 summarizes the results of our considerations regarding tax optimization of the default alternative.

At the boundary between the scenarios $a$ and $b$ $\left(\tau_{c}=\tau_{c^{*}}\right)$, it makes no difference for the terminal value how the temporary increase in capital $E_{0}$ is chosen. The same is applied between scenarios $\mathrm{b}$ and $\mathrm{c}$ regarding the dividend (for $0<\operatorname{Div}_{0}<C_{0}$ ) and for the boundary between scenarios $\mathrm{c}$ and $\mathrm{d}$ regarding the credit-financed dividend. Figure 1 illustrates the terminal values of the four strategies. ${ }^{15}$

${ }^{15}$ The diagram is based on the following values: $C_{0}=100$, $P_{0}=100, i=0.1, D i v_{0}^{\max }=150$. The tax rates are modeled according to the 2007 German tax system $\left(\delta=0.5, a_{i c_{1}}=0.5\right.$, $\left.a_{i c_{2}}=1, a_{c_{1} c_{2}}=1\right)$ and with $\tau_{p}=0.4$ and $\tau_{c_{1}}=0.1667$. 
Figure 1: Terminal value of the default alternative depending on the corporate tax rate on profits

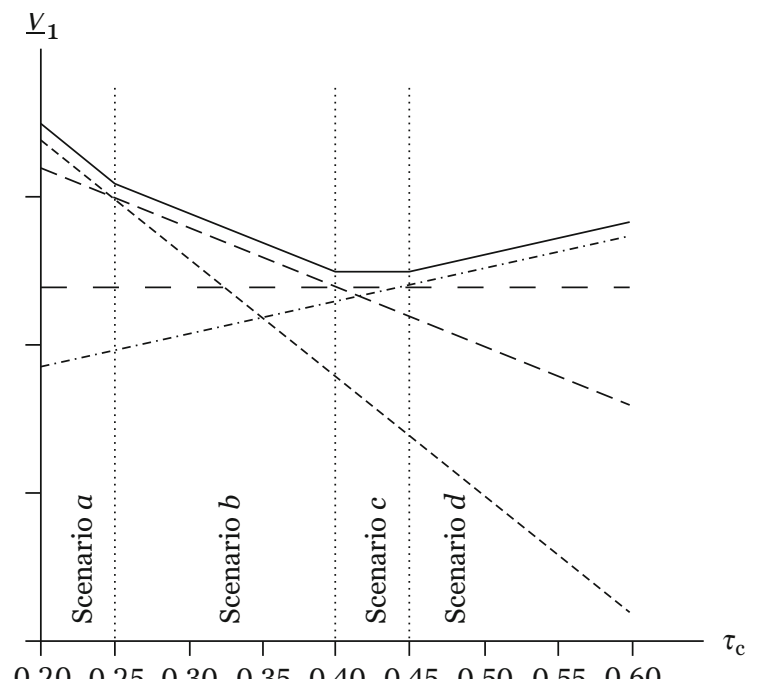

$\begin{array}{lllllllll}0.20 & 0.25 & 0.30 & 0.35 & 0.40 & 0.45 & 0.50 & 0.55 & 0.60\end{array}$

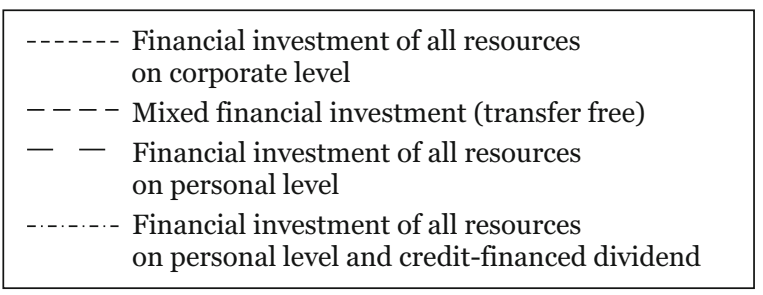

\section{Terminal value of executing the investment project}

\subsection{Options of financing the investment project}

Now we focus on whether the investment project should be carried out or not. In order to realize the project, the firm must raise the amount $I_{0}$ minus the immediate tax refund amounting to $\tau_{c} \beta I_{0}$. The following three sources of financing are available:

1. Internal financing with equity. This means reducing the dividend in $t=0$ (decrease in $\left.D i v_{0}\right)$.

2. External financing with equity (equity financing). This corresponds to an increase in $E_{0}$.

3. External financing with credit capital (credit financing), which results in an increase in $D_{0}$.

One could think of the reduction of a firm's financial investment $\left(M_{0}^{c}\right)$ as an additional financing instrument. However, a glance at the budget restriction of the firm shows that $M_{0}^{c}$ is a pure residuum if one assumes a given investment volume $I_{0}$, given corporate cash resources $C_{0}$ as well as defined values for the three above-mentioned financing instruments.

In fact, a fourth financing source is available if tax is refunded in $t=0$ (due to $\beta>0$ ). However, we assume that $\beta$ is given exogenously and cannot be chosen freely by the firm. Therefore, the investment of the tax authorities does not represent a decision variable.

\subsection{Optimal financing of the investment project}

Whether it is worth executing an investment project must now be examined in detail. It is important to consider that the project is financed tax-optimal. Consequently, the tax-optimized project must be compared with the tax-optimal default alternative regarding the achievable terminal value.

In order to analyze what effects the use of the financing instrument has on the terminal value of the owner, we consider equation (9) and examine how the terminal value changes if we reduce the dividend, temporarily increase the capital and/or increase the credit. The first derivatives of the terminal values are the following:

$$
\begin{aligned}
V_{\text {Div }} & :=-\frac{d V_{1}}{d D i v_{0}}=-i\left(\tau_{c}-\tau_{p}\right)\left(1-\delta \tau_{p}\right) \\
V_{E} & :=\frac{d V_{1}}{d E_{0}}=-i\left(\tau_{c}-\tau_{c^{*}}\right)\left(1-\delta \tau_{p}\right) \\
V_{D} & :=\frac{d V_{1}}{d D_{0}}=-i \tau_{i}\left(1-\delta \tau_{p}\right) .
\end{aligned}
$$

The derivatives $V_{D i v}, V_{E}$ and $V_{D}$ express to what extent the owner's terminal value changes if one required monetary unit for the investment project is made available with the respective financing instrument (reduction of dividend, temporary increase in capital, credit capital increase). ${ }^{16}$ It is important to be aware of the fact that the algebraic sign of the change of the terminal value is not clear in respect to the reduction of dividend and temporary increase in capital. For instance, if the profit tax rate of the firm $\tau_{c}$ is smaller than the tax rates $\tau_{p}$ and $\tau_{c^{*}}$, the derivatives $V_{D i v}$ and $V_{E}$ will become positive. Therefore, internal financing and equity financing will cause the terminal value to

\footnotetext{
${ }^{16}$ For $\beta>0$ amortization also contributes to the financing of the project. This contribution amounts to $V_{\beta}:=d V_{1} / d \beta=$ $I_{0} i \tau_{c}\left(1-\delta \tau_{p}\right)$. However, in the following we assume that amortization regulations are given. Therefore $\beta$ is no decisive variable.
} 
increase. By contrast, if $\tau_{i}>0$ the capital contribution caused by credit financing is always negative, $0>V_{D}$

We will now prove that internal financing from dividend retention is always at least as good as external equity financing (temporary increase in capital) if $\tau_{p} \in(0,1)$ and $\delta \in(0,1]$. We allege that $V_{D i v}>V_{E}$. Inserting and rearranging terms yields the following:

$$
\begin{aligned}
-i\left(\tau_{c}-\tau_{p}\right)\left(1-\delta \tau_{p}\right) & >-i\left(\tau_{c}-\tau_{c^{*}}\right)\left(1-\delta \tau_{p}\right) \\
\tau_{p} & >\tau_{c^{*}} .
\end{aligned}
$$

We have already proven that above.

Now we know that $V_{D i v}>V_{E}$ and $0>V_{D}$ always holds. Under these conditions, six rankings regarding $V_{D i v}, V_{E}, V_{D}$ and $o$ are possible. In analogy to the default alternative, we can distinguish between the following scenarios:

\section{Scenario a: Low corporate tax rate $\left(\tau_{c} \leq \tau_{c^{*}}\right)$}

In this case the following relation holds:

$$
V_{D i v}>V_{E} \geq 0>V_{D} .
$$

We only need to show that $V_{E} \geq 0$. Equation (12) reveals that this is given for the applied assumptions.

\section{Scenario b: Medium corporate tax rate} $\left(\tau_{c^{*}}<\tau_{c} \leq \tau_{p}\right)$

From $\tau_{c} \leq \tau_{p}$ results $V_{D i v} \geq 0$ due to equation (11). Moreover, regarding equation (12) it can be stated that $0>V_{E}$ if $\tau_{c^{*}}<\tau_{c}$. At the current tax rate relation, we obtain the ranking $V_{D i v} \geq 0>V_{E}$. It is hard to decide whether external financing with equity is favorable to external financing with credit capital or vice versa. In order to assess this, we must distinguish between two subsets.

(a) Scenario b1: Debit interest surcharge rate $\tau_{i}$ is high $\left(\tau_{i}>\tau_{c}-\tau_{c^{*}}\right)$

Equations (12) and (13) immediately show that $\tau_{i}>\tau_{c}-\tau_{c^{*}}$ implies the ranking $V_{E}>$ $V_{D}$, which yields the following results:

$$
V_{D i v} \geq 0>V_{E}>V_{D} .
$$

(b) Scenario b2: Debit interest surcharge rate $\tau_{i}$ is low $\left(\tau_{i} \leq \tau_{c}-\tau_{c^{*}}\right)$
Now the reverse is the case. Thus $V_{D} \geq V_{E}$ holds with the result

$$
V_{D i v} \geq 0>V_{D} \geq V_{E} .
$$

\section{Scenario c: High corporate tax rate}

$\left(\tau_{p}<\tau_{c} \leq \tau_{p}+\tau_{i}\right)$

From $\tau_{p}<\tau_{c}$ follows the relation $0>V_{D i v}$ due to equation (11) so that the ranking $0>$ $V_{D i v}>V_{E}$ is given in scenario c. The priority of credit financing cannot be determined without knowing the relation of further tax rates. Again, two subsets must be examined.

(a) Scenario c1: Debit interest surcharge rate $\tau_{i}$ is high $\left(\tau_{i}>\tau_{c}-\tau_{c^{*}} \geq \tau_{c}-\tau_{p}\right)$

From $\tau_{i}>\tau_{c}-\tau_{c^{*}}$ results $V_{E}>V_{D}$, which yields the ranking

$$
0>V_{D i v}>V_{E}>V_{D} .
$$

Raising credit is the least optimal financing alternative.

(b) Scenario c2: Debit interest surcharge rate $\tau_{i}$ is low $\left(\tau_{c}-\tau_{c^{*}} \geq \tau_{i}>\tau_{c}-\tau_{p}\right)$

If the debit interest surcharge rate is lower, external financing with equity capital may be less preferable than external financing with credit capital. With the help of equations (11), (12) and (13), it becomes clear that under the characterized conditions, both $V_{D i v}>V_{D}$ and $V_{D} \geq V_{E}$ hold. Altogether, this yields the following ranking:

$$
0>V_{D i v}>V_{D} \geq V_{E} .
$$

\section{Scenario d: Very high corporate tax rate} $\left(\tau_{p}+\tau_{i}<\tau_{c}\right)$

According to scenario c, the relation $0>V_{\text {Div }}$ results due to $\tau_{p}<\tau_{c}$ from equation (11). Since we already know that $V_{D i v}$ always exceeds $V_{E}$, the ranking $0>V_{D i v}>V_{E}$ is obtained. In order to analyze whether credit financing is preferred to internal and equity financing, the derivatives $V_{D i v}, V_{E}$ and $V_{D}$ have to be compared. As the debit interest surcharge rate $\tau_{i}$ in this scenario turns out to be very low, with $\tau_{c}-\tau_{p}>\tau_{i}$, we have the ranking $0>V_{D}>V_{D i v}$. This becomes clear by considering equations (11) and (13). Therefore, we receive altogether

$$
0>V_{D}>V_{D i v}>V_{E} .
$$


Figure 2: Illustration of alternative scenarios

\begin{tabular}{|c|c|c|c|c|c|}
\hline Scenario a & Scenario b1 & Scenario b2 & \multicolumn{2}{|c|}{ Scenario c2 } & Scenario d \\
\hline$\tau_{c^{*}}$ & \multicolumn{2}{|c|}{$\tau_{c^{*}}+\tau_{i}$} & \multicolumn{3}{|c|}{$\tau_{p}+\tau_{i}$} \\
\hline Scenario a & \multicolumn{2}{|c|}{ Scenario b1 } & Scenario c1 & Scenario c2 & Scenario d \\
\hline & & $\tau_{p}$ & & & \\
\hline
\end{tabular}

Credit financing emerges as the best financing instrument under these circumstances.

In contrast to the default alternative, it does not suffice to verify whether the profit tax rate of the firm is low $\left(\tau_{c} \leq \tau_{c^{*}}\right)$, medium $\left(\tau_{c^{*}}<\tau_{c} \leq \tau_{p}\right)$, high $\left(\tau_{c^{*}} \leq \tau_{p}<\tau_{c} \leq \tau_{p}+\tau_{i}\right)$ or very high $\left(\tau_{p}+\tau_{i}<\tau_{c}\right)$. The implementation of a project with an adequately large investment volume requires financing instruments whose uses should be waived in the default case. In addition, it must be verified whether $\tau_{c} \leq \tau_{c^{*}}+\tau_{i} \leq \tau_{p}+\tau_{i}$ or $\tau_{c^{*}}+\tau_{i}<\tau_{c} \leq \tau_{p}+\tau_{i}$ holds. Illustration 2 shows that there are two mutually exclusive possibilities: either $\tau_{c^{*}}+\tau_{i}<\tau_{p}$ or $\tau_{p} \leq \tau_{c^{*}}+\tau_{i}$

If $\tau_{c^{*}}+\tau_{i}<\tau_{p}$ scenario b2 is relevant; otherwise scenario $\mathrm{c} 1$ is relevant. The following equation must hold for scenario c1 (and not scenario b2) to occur:

$$
\tau_{p}<\frac{(1-\delta) \tau_{p}}{1-\delta \tau_{p}}+\tau_{i}
$$

This quadratic inequation is solved for $\tau_{p}$ with the results

$$
\begin{aligned}
& \tau_{p}<\frac{1+\tau_{i}}{2}-\frac{\sqrt{\delta\left(1+\tau_{i}\right)^{2}-4 \tau_{i}}}{2 \sqrt{\delta}} \text { and } \\
& \tau_{p}>\frac{1+\tau_{i}}{2}+\frac{\sqrt{\delta\left(1+\tau_{i}\right)^{2}-4 \tau_{i}}}{2 \sqrt{\delta}} .
\end{aligned}
$$

As far as the default alternative is concerned, the subsets b1 and b2 must not be distinguished in scenario $b$ because, as the project is not implemented, there is no external financing, neither with equity nor with credits. If the investment is carried out, raising credit or temporarily increasing capital may be necessary. Consequently, the ranking of these financing instruments plays an important role. External financing with equity is more favorable than raising credit in scenario b1. In scenario b2 it is vice versa.

\subsection{Detailed instructions}

For each scenario, the following instructions can be formulated:

Scenario a: Corporate taxation is so low that all investments (the investment project and the financing investment) should be carried out by the corporation. Dividends are not profitable $\left(\operatorname{Div}_{0}=\right.$ $0)$. For the temporary increase in capital - independent of the investment volume - the maximum value $\left(P_{0}\right)$ should be chosen. Credit should only be raised if the available funds on the corporate level (including the amount of the capital increase) $C_{0}+P_{0}$ are insufficient for financing the investment. If $I_{0}\left(1-\beta \tau_{c}\right)>C_{0}+P_{0}$ the difference must be financed by a credit, $D_{0}=I_{0}\left(1-\beta \tau_{c}\right)-\left(C_{0}+P_{0}\right)$.

Scenario b1: Dividends are not profitable due to low corporate taxation, $\operatorname{Div}_{0}=0$. The capital increase should only be chosen if the investment volume exceeds the available funds at the corporate level $C_{0}$. If $C_{0}+P_{0}>I_{0}\left(1-\beta \tau_{c}\right)>C_{0}$ then $E_{0}=$ $I_{0}\left(1-\beta \tau_{c}\right)-C_{0}$ must be chosen. The temporary capital increase is still much more preferable to the external financing with credit capital, which is only chosen if the capital increase is insufficient for financing the investment project. If $I_{0}\left(1-\beta \tau_{c}\right)>$ $C_{0}+P_{0}$ then $E_{0}=P_{0}$ and $D_{0}=I_{0}\left(1-\beta \tau_{c}\right)-\left(C_{0}+P_{0}\right)$ is set.

Scenario b2: Corporate taxation is still too low for a dividend distribution to be profitable, $D i v_{0}=$ 0 . The disadvantage of external credit financing is now less than that of external equity financing. If corporate funds $C_{0}$ are insufficient for financing the investment project completely, the shortfall must be financed by a credit. If $I_{0}\left(1-\beta \tau_{c}\right)>C_{0}$ then $D_{0}=I_{0}\left(1-\beta \tau_{c}\right)-C_{0}$ must be chosen. The temporary increase in capital is not profitable, $E_{0}=0$.

Scenario c1: In this scenario corporate taxation is high enough for a dividend distribution to be advantageous compared to the default alternative. However, a dividend retention is the best financing method if the project is carried out. If the project's investment volume is lower than the corporate financial resources, the project must be financed from these funds and the remaining amount has to be distributed. If $I_{0}\left(1-\beta \tau_{c}\right) \leq C_{0}$ 
Table 3: Optimal financing of the investment project: Scenarios, subsets and instructions (continued on next page)

\begin{tabular}{|c|c|c|c|c|c|c|c|c|}
\hline \multirow{2}{*}{\multicolumn{2}{|c|}{ Scenario }} & \multirow{2}{*}{\multicolumn{2}{|c|}{$\mathbf{a}$}} & \multicolumn{5}{|c|}{ b } \\
\hline & & & & \multicolumn{3}{|c|}{ b1 } & \multicolumn{2}{|c|}{ b2 } \\
\hline \multirow{2}{*}{\multicolumn{2}{|c|}{ Tax rates }} & \multirow{2}{*}{\multicolumn{2}{|c|}{$\tau_{c} \leq \tau_{c^{*}}$}} & \multicolumn{5}{|c|}{$\tau_{c^{*}}<\tau_{c} \leq \tau_{p}$} \\
\hline & & & & \multicolumn{3}{|c|}{$\tau_{i}>\tau_{c}-\tau_{c^{*}}$} & \multicolumn{2}{|c|}{$\tau_{i} \leq \tau_{c}-\tau_{c^{*}}$} \\
\hline \multicolumn{2}{|c|}{$\begin{array}{l}\text { Ranking of the } \\
\text { derivatives }\end{array}$} & \multicolumn{2}{|c|}{$V_{D i v}>V_{E} \geq 0>V_{D}$} & \multicolumn{3}{|c|}{$V_{D i v} \geq 0>V_{E}>V_{D}$} & \multicolumn{2}{|c|}{$V_{D i v} \geq 0>V_{D} \geq V_{E}$} \\
\hline \multicolumn{2}{|l|}{$\begin{array}{l}\text { General } \\
\text { instructions }\end{array}$} & \multicolumn{2}{|c|}{$\begin{array}{l}\operatorname{Div}_{0}=0 \\
E_{0}=P_{0} \\
D_{0} \text { only if necessary }\end{array}$} & \multicolumn{3}{|c|}{$\begin{array}{l}\operatorname{Div}_{0}=0 \\
E_{0} \text { only if necessary } \\
D_{0} \text { only if necessary }\end{array}$} & \multicolumn{2}{|c|}{$\begin{array}{l}D_{i v_{0}}=0 \\
D_{0} \text { only if necessary } \\
E_{0}=0\end{array}$} \\
\hline \multicolumn{2}{|l|}{ Subsets } & $I_{0}^{*} \leq C_{0}+P_{0}$ & $I_{0}^{*}>C_{0}+P_{0}$ & $I_{0}^{*} \leq C_{0}$ & $C_{0}<I_{0}^{*} \leq C_{0}+P_{0}$ & $I_{0}^{*}>C_{0}+P_{0}$ & $I_{0}^{*} \leq C_{0}$ & $I_{0}^{*}>C_{0}$ \\
\hline \multirow{3}{*}{$\begin{array}{l}\text { Detailed } \\
\text { instructions }\end{array}$} & $\operatorname{Div}_{0}$ & 0 & 0 & 0 & 0 & 0 & 0 & 0 \\
\hline & $E_{0}$ & $P_{0}$ & $P_{0}$ & 0 & $I_{0}^{*}-C_{0}$ & $P_{0}$ & 0 & 0 \\
\hline & $D_{0}$ & 0 & $I_{0}^{*}-\left(C_{0}+P_{0}\right)$ & 0 & 0 & $I_{0}^{*}-\left(C_{0}+P_{0}\right)$ & 0 & $I_{0}^{*}-C_{0}$ \\
\hline \multicolumn{2}{|l|}{ Constellation } & 1 & 2 & 3 & 4 & 5 & $=3^{*}$ & 6 \\
\hline
\end{tabular}

*: These are no separate constellations, because they coincide with constellations 3 and 7 with respect to the instructions in case of the realization of the project as well as in case of the default alternative.

$I_{0}^{*}$ stands for $I_{0}\left(1-\beta \tau_{c}\right)$.

then $\operatorname{Div}_{0}=C_{0}-I_{0}\left(1-\beta \tau_{c}\right)$ is to be chosen. Only if corporate capital $C_{0}$ is insufficient for financing the investment project must the shortfall be financed through a temporary increase in capital. If $I_{0}\left(1-\beta \tau_{c}\right)>C_{0}$ then $E_{0}=I_{0}\left(1-\beta \tau_{c}\right)-C_{0}$ should be chosen. Only if these funds are insufficient for financing the investment (despite the increase in capital), must the difference be financed by a credit. Consequently if $I_{0}\left(1-\beta \tau_{c}\right)>C_{0}+P_{0}$ the optimal credit amounts to $D_{0}=I_{0}\left(1-\beta \tau_{c}\right)-\left(C_{0}+P_{0}\right)$.

Scenario c2: According to c1, corporate taxation is so high that a dividend distribution with the following personal financial investment would be advantageous compared to the default alternative. Reducing the dividend is the best financing source if the project is to be realized. If the investment project can be financed completely using corporate funds, then the remaining amount is to be distributed. If $I_{0}\left(1-\beta \tau_{c}\right) \leq C_{0}$ then $D i v_{0}=C_{0}-I_{0}\left(1-\beta \tau_{c}\right)$ must be chosen. Only if corporate cash resources $C_{0}$ are insufficient for financing the project must the shortfall be financed through a credit. If $I_{0}\left(1-\beta \tau_{c}\right)>C_{0}$ then choosing $D_{0}=I_{0}\left(1-\beta \tau_{c}\right)-C_{0}$ is optimal. External financing with equity is not profitable, therefore $E_{0}=0$.

Scenario d: Corporate taxation is even higher than in scenarios c1 and c2. Consequently, a max- imum dividend distribution $D i v_{0}=D i v_{0}^{\max }$ with a following privately funded deposit is worth it, independently of whether the investment project is carried out. The project as well as the dividend must be financed by corporate cash resources $C_{0}$ and credit $D_{0}$. This results in $C_{0}+D_{0}=I_{0}\left(1-\beta \tau_{c}\right)+$ $D i v_{0}^{\max }$. Consequently, $D_{0}=I_{0}\left(1-\beta \tau_{c}\right)+D i v_{0}^{\max }-C_{0}$ is set. Again, external financing with equity is not profitable, therefore $E_{0}=0$.

Table 3 provides an overview of the six scenarios as well as the instructions.

\subsection{Terminal value differences for all possible constellations}

Table 3 shows that there are 11 different constellations. Each of these combinations contains

- an optimal financing program for the scenario,

- the particular investment volume for the realization, and

- a complete program for the default alternative.

The specific terminal value formulas for each of these 11 combinations are derived according to a uniform pattern.

We describe the general procedure using constellation 6 in Table 3 as an example. This corresponds to scenario b2 subject to condition $I_{0}\left(1-\beta \tau_{c}\right)>C_{0}$. 
Table 3: (continued)

\begin{tabular}{|c|c|c|c|c|c|}
\hline \multicolumn{5}{|c|}{ c } & \multirow[t]{2}{*}{ d } \\
\hline \multicolumn{3}{|c|}{ c1 (alternative of b2) } & \multicolumn{2}{|c|}{ c2 } & \\
\hline \multicolumn{5}{|c|}{$\tau_{p}<\tau_{c} \leq \tau_{p}+\tau_{i}$} & \multirow[t]{2}{*}{$\tau_{p}+\tau_{i}<\tau_{c}$} \\
\hline \multicolumn{3}{|c|}{$\tau_{i}>\tau_{c}-\tau_{c^{*}} \geq \tau_{c}-\tau_{p}$} & \multicolumn{2}{|c|}{$\tau_{c}-\tau_{c^{*}} \geq \tau_{i}>\tau_{c}-\tau_{p}$} & \\
\hline \multicolumn{3}{|c|}{$0>V_{D i v}>V_{E}>V_{D}$} & \multicolumn{2}{|c|}{$0>V_{D i v}>V_{D} \geq V_{E}$} & $0>V_{D}>V_{D i v}>V_{E}$ \\
\hline \multicolumn{3}{|c|}{$\begin{array}{l}\text { reduction of dividends only if necessary } \\
E_{0} \text { only if necessary } \\
D_{0} \text { only if necessary }\end{array}$} & \multicolumn{2}{|c|}{$\begin{array}{l}\text { reduction of dividends only } \\
\text { if necessary } \\
D_{0} \text { only if necessary } \\
E_{0}=0\end{array}$} & $\begin{array}{l}D_{0}=I_{0}^{*}+D i v_{0}^{\max }-C_{0} \\
D i v_{0}=D i v_{0}^{\max } \\
E_{0}=0\end{array}$ \\
\hline$I_{0}^{*} \leq C_{0}$ & $C_{0}<I_{0}^{*} \leq C_{0}+P_{0}$ & $I_{0}^{*}>C_{0}+P_{0}$ & $I_{0}^{*} \leq C_{0}$ & $I_{0}^{*}>C_{0}$ & \\
\hline$C_{0}-I_{0}^{*}$ & 0 & 0 & $C_{0}-I_{0}^{*}$ & 0 & $D i v_{0}^{\max }$ \\
\hline 0 & $I_{0}^{*}-C_{0}$ & $P_{0}$ & 0 & 0 & 0 \\
\hline 0 & 0 & $I_{0}^{*}-\left(C_{0}+P_{0}\right)$ & 0 & $I_{0}^{*}-C_{0}$ & $I_{0}^{*}+D i v_{0}^{\max }-C_{0}$ \\
\hline 7 & 8 & 9 & $=7^{*}$ & 10 & 11 \\
\hline
\end{tabular}

1. First, the terminal value is calculated if the project is realized according to equation (9), which is repeated as follows.

$$
\begin{aligned}
\bar{V}_{1}= & \left(-I_{0}\left(1+i\left(1-\beta \tau_{c}\right)\right)+C F_{1}\right) \\
& \times\left(1-\tau_{c}\right)\left(1-\delta \tau_{p}\right) \\
& +P_{0}\left(1+i\left(1-\tau_{p}\right)\right) \\
& +C_{0}\left(1+i\left(1-\tau_{c}\right)\right)\left(1-\delta \tau_{p}\right) \\
& +D_{i} i v_{0} i\left(\tau_{c}-\tau_{p}\right)\left(1-\delta \tau_{p}\right) \\
& -E_{0} i\left(\tau_{c}-\tau_{c^{*}}\right)\left(1-\delta \tau_{p}\right) \\
& -D_{0} i \tau_{i}\left(1-\delta \tau_{p}\right) .
\end{aligned}
$$

The determinations of the financing instruments characterized in constellation 6 are:

$$
\begin{aligned}
& \operatorname{Div}_{0}=0, \\
& E_{0}=0 \text { and } \\
& D_{0}=I_{0}\left(1-\beta \tau_{c}\right)-C_{0} .
\end{aligned}
$$

With these specifications, the aforementioned terminal value equation reduces to

$$
\text { (15) } \begin{aligned}
\bar{V}_{1}^{(6)}= & \left(-I_{0}\left(1+i\left(1-\beta \tau_{c}\right)\right)+C F_{1}\right) \\
& \times\left(1-\tau_{c}\right)\left(1-\delta \tau_{p}\right) \\
& +P_{0}\left(1+i\left(1-\tau_{p}\right)\right) \\
& +C_{0}\left(1+i\left(1-\tau_{c}\right)\right)\left(1-\delta \tau_{p}\right) \\
& -\left(I_{0}\left(1-\beta \tau_{c}\right)-C_{0}\right) \\
& \times i \tau_{i}\left(1-\delta \tau_{p}\right) .
\end{aligned}
$$

2. The default alternative yields a terminal value in scenario $b$ as follows:

$$
\text { (16) } \begin{aligned}
\underline{V}_{1}^{b}= & P_{0}\left(1+i\left(1-\tau_{p}\right)\right) \\
& +C_{0}\left(1+i\left(1-\tau_{c}\right)\right)\left(1-\delta \tau_{p}\right) .
\end{aligned}
$$

3. The terminal value difference for combination number 6 amounts to

$$
\Delta V_{1}^{(6)}=\bar{V}_{1}^{(6)}-\underline{V}_{1}^{b},
$$

for which the following formula is obtained by inserting equations (15) and (16) and after appropriate reformulation:

$$
\begin{aligned}
\Delta V_{1}^{(6)}= & \left(\left(-I_{0}\left(1+i\left(1-\beta \tau_{c}\right)\right)+C F_{1}\right)\right. \\
& \left.\times\left(1-\tau_{c}\right)-\left(I_{0}\left(1-\beta \tau_{c}\right)-C_{0}\right) i \tau_{i}\right) \\
& \times\left(1-\delta \tau_{p}\right) .
\end{aligned}
$$

Table 4 supplies a complete overview of the determined terminal value differences. If we take a closer look at these differences, some of the results are quite remarkable.

1. There are four constellations where neither corporate nor personal cash resources have to be known. Both $C_{0}$ and $P_{0}$ are irrelevant to the calculation of the terminal value difference. This is the case for constellations 1,3 , 
Table 4: Complete overview of all terminal value differences

\begin{tabular}{|c|c|}
\hline Constellation & $\Delta V_{1}=\bar{V}_{1}-\underline{V}_{1}$ \\
\hline 1 & $\Delta V_{1}^{(1)}=\left(-I_{0}\left(1+i\left(1-\beta \tau_{c}\right)\right)+C F_{1}\right)\left(1-\tau_{c}\right)\left(1-\delta \tau_{p}\right)$ \\
\hline 2 & $\Delta V_{1}^{(2)}=\left(\left(-I_{0}\left(1+i\left(1-\beta \tau_{c}\right)\right)+C F_{1}\right)\left(1-\tau_{c}\right)-\left(I_{0}\left(1-\beta \tau_{c}\right)-\left(C_{0}+P_{0}\right)\right) i \tau_{i}\right)\left(1-\delta \tau_{p}\right)$ \\
\hline 3 & $\Delta V_{1}^{(3)}=\left(-I_{0}\left(1+i\left(1-\beta \tau_{c}\right)\right)+C F_{1}\right)\left(1-\tau_{c}\right)\left(1-\delta \tau_{p}\right)$ \\
\hline 4 & $\Delta V_{1}^{(4)}=\left(\left(-I_{0}\left(1+i\left(1-\beta \tau_{c}\right)\right)+C F_{1}\right)\left(1-\tau_{c}\right)-\left(I_{0}\left(1-\beta \tau_{c}\right)-C_{0}\right) i\left(\tau_{c}-\tau_{c^{*}}\right)\right)\left(1-\delta \tau_{p}\right)$ \\
\hline 5 & $\begin{aligned} \Delta V_{1}^{(5)}= & \left(\left(-I_{0}\left(1+i\left(1-\beta \tau_{c}\right)\right)+C F_{1}\right)\left(1-\tau_{c}\right)-I_{0}\left(1-\beta \tau_{c}\right) i \tau_{i}\right. \\
& \left.+P_{0} i\left(\tau_{c^{*}}+\tau_{i}-\tau_{c}\right)+C_{0} i \tau_{i}\right)\left(1-\delta \tau_{p}\right)\end{aligned}$ \\
\hline 6 & $\Delta V_{1}^{(6)}=\left(\left(-I_{0}\left(1+i\left(1-\beta \tau_{c}\right)\right)+C F_{1}\right)\left(1-\tau_{c}\right)-\left(I_{0}\left(1-\beta \tau_{c}\right)-C_{0}\right) i \tau_{i}\right)\left(1-\delta \tau_{p}\right)$ \\
\hline 7 & $\Delta V_{1}^{(7)}=\left(\left(-I_{0}\left(1+i\left(1-\beta \tau_{c}\right)\right)+C F_{1}\right)\left(1-\tau_{c}\right)-I_{0}\left(1-\beta \tau_{c}\right) i\left(\tau_{c}-\tau_{p}\right)\right)\left(1-\delta \tau_{p}\right)$ \\
\hline 8 & $\begin{aligned} \Delta V_{1}^{(8)}= & \left(\left(-I_{0}\left(1+i\left(1-\beta \tau_{c}\right)\right)+C F_{1}\right)\left(1-\tau_{c}\right)-I_{0}\left(1-\beta \tau_{c}\right) i\left(\tau_{c}-\tau_{c^{*}}\right)\right. \\
& \left.+C_{0} i\left(\tau_{p}-\tau_{c^{*}}\right)\right)\left(1-\delta \tau_{p}\right)\end{aligned}$ \\
\hline 9 & $\begin{aligned} \Delta V_{1}^{(9)}= & \left(\left(-I_{0}\left(1+i\left(1-\beta \tau_{c}\right)\right)+C F_{1}\right)\left(1-\tau_{c}\right)-I_{0}\left(1-\beta \tau_{c}\right) i \tau_{i}\right. \\
& \left.+P_{0} i\left(\tau_{c^{*}}+\tau_{i}-\tau_{c}\right)+C_{0} i\left(\tau_{p}+\tau_{i}-\tau_{c}\right)\right)\left(1-\delta \tau_{p}\right)\end{aligned}$ \\
\hline 10 & $\begin{aligned} \Delta V_{1}^{(10)}= & \left(\left(-I_{0}\left(1+i\left(1-\beta \tau_{c}\right)\right)+C F_{1}\right)\left(1-\tau_{c}\right)-I_{0}\left(1-\beta \tau_{c}\right) i \tau_{i}\right. \\
& \left.+C_{0} i\left(\tau_{p}+\tau_{i}-\tau_{c}\right)\right)\left(1-\delta \tau_{p}\right)\end{aligned}$ \\
\hline 11 & $\Delta V_{1}^{(11)}=\left(\left(-I_{0}\left(1+i\left(1-\beta \tau_{c}\right)\right)+C F_{1}\right)\left(1-\tau_{c}\right)-I_{0}\left(1-\beta \tau_{c}\right) i \tau_{i}\right)\left(1-\delta \tau_{p}\right)$ \\
\hline
\end{tabular}

7 and 11. Moreover, it is remarkable that the terminal value differences of constellations 1 and 3 are completely identical, although their default alternatives do not correspond in both constellations.

2. Only in three constellations (2, 5 and 9) is information about personal cash resources necessary.

3. For $\beta=0$ (amortization only in $t=1$ ), in each of these equations the "project's contribution to the terminal value in a world without taxes"17 is completely subject to corporate tax $\left(\tau_{c}\right)$ and delta-income tax $\left(\delta \tau_{p}\right)$. Indeed, these taxes determine the amount of the terminal value contribution, but not its algebraic sign. The determination of the taxable profit is not influenced by the choice of $\beta$ and is therefore decision-neutral. In general, the delta-income tax has only two decisive effects:

- In constellations 4 and $5, \tau_{c^{*}}$ affects the terminal value difference through the type of financing. $\tau_{c^{*}}$ itself is determined by the delta-income tax, because $\tau_{c^{*}}=(1-$ $\delta) \tau_{p} /\left(1-\delta \tau_{p}\right)$.

${ }^{17}$ That is $-I_{0}(1+i)+C F_{1}$.
- With the help of $\tau_{c^{*}}$, the delta-income tax has an influence on what scenario and which constellation will occur.

$\Delta V_{1}^{(1)}$ shall be considered an example. The income tax rate as well as the shareholder relief system, which implies a prorated inclusion of dividends in the tax base, influence the absolute amount of the terminal value difference. However, at $\beta=0$ a positive terminal value difference before income tax remains positive for $\tau_{p} \in(0,1)$; the same is true for cases of negative terminal value differences.

4. For $\beta>0$ (amortization in $t=0$ ), the recognition of profits turns out to be a tax concession: An investment project with a negative terminal value-difference before tax can obtain a positive terminal value-difference after taxes. The size of the effect depends on the interest rate because the advantage of the immediate amortization is a pure interest advantage in our model. $^{18}$

\subsection{A remark on net present values}

The terminal value-differences from Table 4 could also be reinterpreted as net present values. Con-

\footnotetext{
${ }^{18}$ Concerning the taxation paradox, see, e.g., Schneider (1969).
} 
sidering the terminal value-difference for constellation 1 as an example, it can only be positive if and only if

$$
-I_{0}\left(1+i\left(1-\beta \tau_{c}\right)\right)+C F_{1}>0 .
$$

This inequation can be transferred either to

$$
-I_{0}+\frac{C F_{1}}{1+i\left(1-\beta \tau_{c}\right)}>0
$$

or

$$
-I_{0}+\frac{C F_{1}+\beta \tau_{c} I_{0}}{1+i}>0 .
$$

Readers may attempt to interpret the left side as net present value. The investment is profitable if the discounted sum of the gross cash flow plus the tax advantages caused by the amortization exceed the investment payment. However, caution is required with such intuitive interpretations.

It is beyond dispute in the literature that the net present value of an investment project under the conditions of a so-called complete capital market can be interpreted as the amount available for withdrawal in $t=0$, which can be expended without being positioned worse at the realization of the project than at the choice of the default alternative. If the capital market is not complete, such a critical immediate withdrawal can be calculated as well. However, it is known that an investor who maximizes the terminal value does not make the same decisions as investors who want to maximize the withdrawal in $t=0$. In our model we assume identical gross-interest rates for creditors and debtors. However, we cannot assume that the after-tax interest rates correspond.

In fact, the above mentioned inequations are advisable for persons maximizing their terminal values under the condition of constellation 1 but it is inappropriate to interpret the left sides as net present values.

\section{Numerical examples}

\subsection{Application to the German tax system}

We now want to show how the model can be applied to an existing tax system. For convenience reasons, we choose the German 2007 tax system. In Germany, the firm pays local business tax and corporate income tax. German local business tax allows only a partial deduction of interest paid for permanent debt. We assume loans taken out by the firm are to be characterized as permanent debts.

Regarding the current tax reform as well as possible future tax reforms in Germany, we distinguish between

- $a_{i c_{1}} \in[0,1]$ as the deductible part of the interest on permanent debt for local business tax purposes,

- $a_{i c_{2}} \in[0,1]$ as the deductible part of the interest on permanent debt for corporate income tax purposes and

- $a_{c_{1} c_{2}} \in[0,1]$ as the deductible part of the local business tax costs for corporate income tax purposes.

So the profit tax of the firm in $t=1$ is

$$
\begin{aligned}
& T_{1}^{c}=\underbrace{\tau_{c_{1}}\left(C F_{1}-(1-\beta) I_{0}+i M_{0}^{c}-a_{i c_{1}} i D_{0}\right)}_{\text {Local business tax }} \\
& +\underbrace{\left[\begin{array}{r}
\tau_{c_{2}}\left(C F_{1}-(1-\beta) I_{0}+i M_{0}^{c}-a_{i c_{2}} i D_{0}\right. \\
-a_{c_{1} c_{2}} \tau_{c_{1}}\left(C F_{1}-(1-\beta) I_{0}+i M_{0}^{c}\right. \\
\left.\left.-a_{i c_{1}} i D_{0}\right)\right)
\end{array}\right]}_{\text {Corporate income tax }},
\end{aligned}
$$

where $\tau_{c_{1}}$ stands for the local business tax rate and $\tau_{c_{2}}$ stands for the corporate income tax rate (including solidarity surcharge). From this we derive the tax multifactors

$$
\begin{aligned}
& \tau_{c}=\tau_{c_{1}}+\left(1-a_{c_{1} c_{2}} \tau_{c_{1}}\right) \tau_{c_{2}} \quad \text { and } \\
& \tau_{i}=\tau_{c_{1}}\left(1-a_{i c_{1}}\right)\left(1-a_{c_{1} c_{2}} \tau_{c_{2}}\right)+\tau_{c_{2}}\left(1-a_{i c_{2}}\right) .
\end{aligned}
$$

So the tax equation of the firm for $t=1$ is:

$$
\begin{aligned}
T_{1}^{c}= & \tau_{c}\left(C F_{1}-(1-\beta) I_{0}+i\left(M_{0}^{c}-D_{0}\right)\right) \\
& +\tau_{i} i D_{0}
\end{aligned}
$$

Now we can elicit which of the scenarios b2 and c1 may be ruled out. For this purpose, we apply inequation (14). Even if a very high municipal rate of $500 \%$ is assumed for calculating the local business tax rate, the income tax rate (including solidarity surcharge rate) has to be below $16.5 \%$ or above $91.0 \%$ according to the current German tax system $^{19}$ if these inequations are to be fulfilled. At the moment, such low or high margin-income tax

$\overline{{ }^{19} \delta=a_{i c_{1}}=0.5 \text { as well as } a_{i c_{2}}=a_{c_{1} c_{2}}=1}$ and $\tau_{c_{2}}=0.25$. 
rates (beyond the poverty level) are not realistic. Therefore, scenario b2 is relevant in the current German taxation system.

In order to show the apparent tax effects in our model, we analyze two numerical examples with the following characteristics. The cash resources of the corporation amount to $C_{0}=41$. There are personal financial resources amounting to $P_{0}=$ 20 . The interest rate is $i=10 \%$. An income tax rate of $\tau_{p}=0.44$ and a local business tax rate of $\tau_{c_{1}}=0.167$ (municipal rate of $400 \%$ ) is assumed. For the deduction of the interest on debts and the local business tax at the profit taxes, the current German tax system is assumed: $a_{i c_{1}}=0.50, a_{i c_{2}}=$ $1.00, a_{c_{1} c_{2}}=1.00$. The recognition of profits is decision-neutral $(\beta=0)$. On this basis we consider terminal value differences depending on the profit tax rate $\tau_{c}$ (local business tax and corporate income tax) for three project variants.

- In the first variant (continuous line), a low investment volume $\left(I_{0}<C_{0}\right)$ is assumed, $I_{0}=$ 40.

- In the second variant (interrupted line), $C_{0}$ by itself is insufficient for financing the investment project $\left(C_{0}<I_{0}<C_{0}+P_{0}\right), I_{0}=60$.

- In the third variant (dotted line), the investment volume is so high that it cannot be financed without raising a credit $\left(I_{0}>C_{0}+P_{0}\right)$, $I_{0}=100$.

For each investment project, we assume a gross return of $10.3 \%$ so that all three projects are advantageous before tax and their terminal value contribution increases with the investment volume.

If taxes are included in the analysis, that statement no longer holds. Figure 3 shows clearly that the benefit of a project is dependent on the corporate tax rate, despite decision-neutral amortizations. Where the corporate tax rate is low $\left(\tau_{c}<0.25\right)$, the project with the medium investment volume (interrupted line) achieves the highest terminal value contribution. The terminal value contribution of the project with the highest investment volume (dotted line) is always negative. The reason for that is that fiscal discrimination of credit interest payments cannot be avoided with a high investment volume. From a corporate tax rate of approximately $43 \%$ and above, the terminal value
Figure 3: Terminal value differences depending on corporate tax rates on profits (example 1)

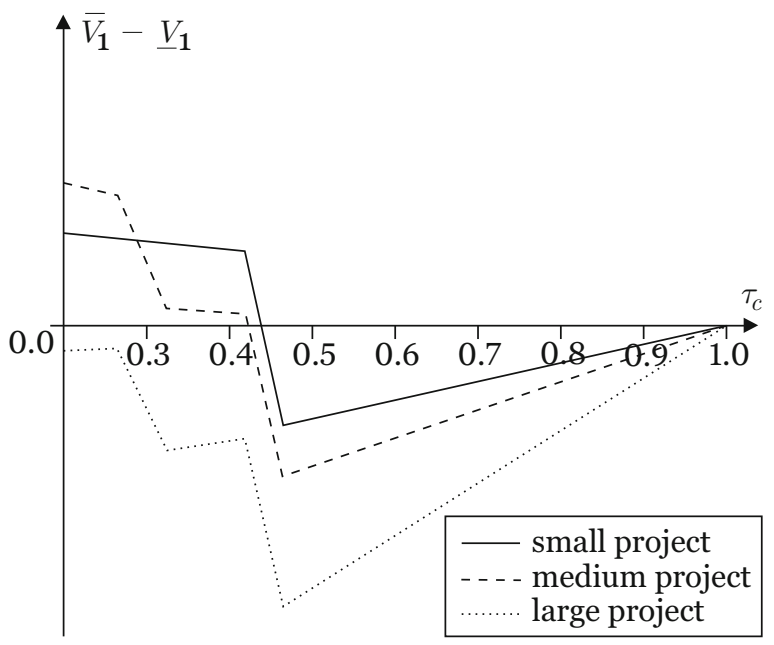

contributions of all three investment projects are negative.

We observe that the terminal value differences do not behave monotonously in relation to the profit tax rate of the firm. In fact, the functions show local maxima and minima. An explanation is necessary. For this purpose, we consider the same example as before, however this time ensuring that for each investment volume, an identical terminal value difference before taxes is given. In order to explain the apparently random increase and decrease of the functions, we focus on the project with the medium investment volume (interrupted line). The following can be stated for this project:

Figure 4: Terminal value differences depending on corporate tax rates on profits (example 2)

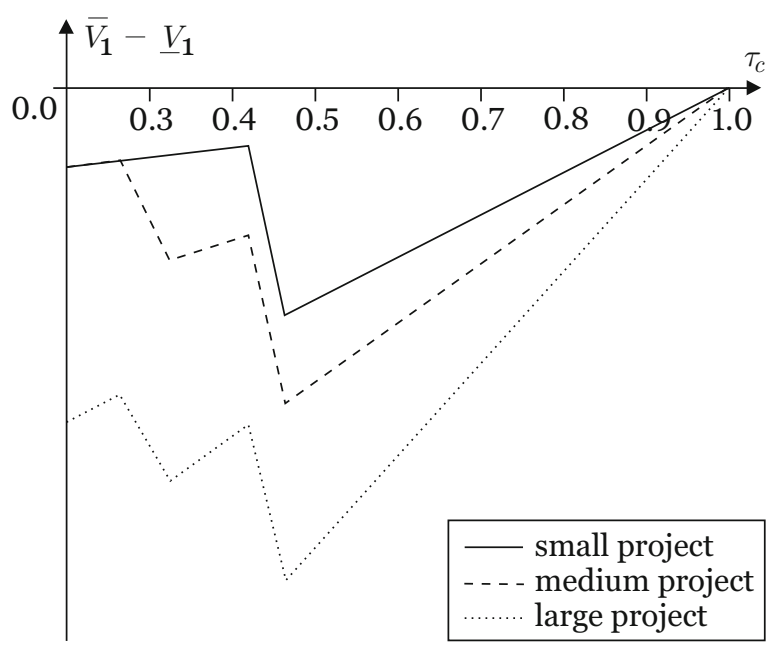


At a firm's income tax rate of up to $\tau_{c}=0.265$, constellation 1 is relevant. The project with a volume of 60 and a financial investment in the amount of 1 are financed by corporate cash resources $C_{0}=41$ and by a temporary increase in capital amounting to $E_{0}=20$. If the corporate tax rates ranges between 0.265 and 0.33 , constellation 4 is applied. For corporate tax rates between 0.33 and 0.415 , constellation 6 is applied. If the corporate tax rate is between 0.415 and 0.47 , constellation 10 is relevant. If the corporate tax rate exceeds 0.47 , constellation 11 is applied.

\subsection{Country comparison}

In the Table 5, we show for selected countries which scenario is relevant. The corporate tax rate $\tau_{c}$ is the marginal rate for high profits. The debit interest surcharge rate $\tau_{i}$ is the marginal rate for paid interest on debt. The personal income tax rate $\tau_{p}$ is the maximum marginal rate on interest income. Options for the taxpayers not to choose the shareholder relief system and other exceptions were neglected.

Table 5: Scenarios for selected countries

\begin{tabular}{llllll} 
Country & $\boldsymbol{\tau}_{\boldsymbol{c}}$ & $\boldsymbol{\tau}_{\boldsymbol{i}}$ & $\boldsymbol{\tau}_{\boldsymbol{p}}{ }^{1}$ & $\boldsymbol{\delta}$ & Scenario \\
\hline Austria 2007 & 0.25 & 0.00 & 0.25 & 1 & $\mathrm{~b} 2$ \\
\hline Germany 2007 $^{2}$ & 0.39 & 0.06 & 0.47 & 0.5 & $\mathrm{~b} 2$ \\
\hline Germany 2009 $^{2}$ & 0.30 & 0.04 & 0.26 & 1 & $\mathrm{c} 2$ \\
\hline Ireland 2007 $^{2}$ & 0.13 & 0.00 & 0.41 & 1 & $\mathrm{~b} 2$ \\
\hline Slovakia 2007 & 0.19 & 0.00 & 0.19 & 0 & $\mathrm{a}$ \\
\hline
\end{tabular}

${ }^{1}$ maximum rate; ${ }^{2}$ municipal rate $400 \%$

\section{Conclusion}

We have presented the evaluation of an indivisible investment carried out in a corporation. One should think that this problem is not too difficult because certainty, the domestic case, only one owner subject to income tax and proportional tax rates are presumed. Moreover, the problems of accrual taxation are only considered in a very simplified way with respect to only two payment date points.

It is surprising that the evaluation under these simple premises is such a complex challenge. The reason for this is mainly the separate taxation of the corporation and owner (separation principle). The financing of the investment project with external equity capital, external credit capital or through a dividend retention as well as the definition of the default alternative require diverse case differentiations.

Under the German tax system for $2007\left(\tau_{c_{2}}=0.25\right.$, moiety adding of interest on permanent debt for local business tax purposes) and for positive income tax rates, the relevant scenario is characterized as follows: Internal financing from dividend retention is - whether the project is realized or not advantageous. Any capital shortfall should be financed by credits. Temporary increases in capital should be waived.

Some general tendencies are recognizable, independently of what tax regime applies. Raising credit capital is unprofitable since for local business tax purposes, only a part of the interest on permanent debt is deductible. In case of the default alternative, external credit financing of an additional financial investment is not feasible. However, external credit financing can be preferable to equity financing when corporate tax rates are relatively high. If internal financing capacities are exhausted in an investment, it depends on the individual case whether equity financing or credit financing are more suitable. In the extreme cases of very high corporate tax rates, external credit financing is even better than financing from dividend retention.

For the choice between external equity financing and internal financing (as well as deciding whether a financial investment should occur on the corporate or owner level at the default alternative), the following applies: The temporary increase in capital is never preferable to financing by dividend retention. The higher the corporate tax rate relative to the income tax rate, the less preferable is equity financing, and the more profitable is a financial investment at the owner level in case of the default alternative. In this case, however, calculating the terminal value differences is exceptionally laborious.

We have not considered possible exogenous restrictions such as dividend obligations which are imposed on the corporation by shareholders. Such restrictions are caused by information asymmetries and interest conflicts in the principal-agent relation between management and shareholders. Our model is neither suitable nor intended to illustrate such principal-agent problems. 


\section{References}

Auerbach, Alan J. (2002): Taxes and corporate financial policy, in: Auerbach, A. J.; Feldstein, M. (eds.), Handbook of Public Economics 3, Elsevier, Amsterdam, 1251-1289.

Elser, Thomas (2001): Warum die GmbH nur selten als Spardose taugt, Betriebsberater, 56 (16): 805-810.

Graham, John R. (2006): A review of taxes and corporate finance, Foundations and Trends in Finance, 2 (1): 573-691.

Gratz, Kurt (2002): Finanzierungs- und Ausschüttungsstrategien der mittelständischen GmbH, Der Betrieb, 55 (10): 489494.

Haase, Klaus Dittmar and Markus Diller (2002): Steueroptimale Finanzierung einer personenbezogenen Kapitalgesellschaft, Der Betrieb, 55 (5): 229-230.

Hassett, Kevin A. and R. Glenn Hubbard (2002): Tax policy and business investment, in: Auerbach, A.J.; Feldstein, M. (eds.), Handbook of Public Economics 3, Elsevier, Amsterdam, 1293-1343.

Hundsdoerfer, Jochen (2001): Halbeinkünfteverfahren und Lock-In-Effekt, Steuer und Wirtschaft, 31 (2): 113-125.

Husmann, Sven (2007): Bewertung von Investitionsprojekten bei steuerlich optimaler Finanzierung, Die Betriebswirtschaft, 67 (4): 369-380.

Husmann, Sven and Lutz Kruschwitz (2001): Ein Standardmodell der Investitionsrechnung für deutsche Kapitalgesellschaften, FinanzBetrieb, 3 (12): 641-644.

Husmann, Sven and Lutz Kruschwitz (2002): Korrektur zum Beitrag: Ein Standardmodell der Investitionsrechnung für deutsche Kapitalgesellschaften, FinanzBetrieb, 4 (6/8): 442.

Kaplow, Louis (2006): Taxation, NBER working paper 12061, National Bureau of Economic Research, Cambridge, Mass.

Kiesewetter, Dirk and Maik Dietrich (2007): Ein Standardmodell für Investitionsentscheidungen in Kapitalgesellschaften, Wirtschaftswissenschaftliches Studium, 36 (5): 235-244.

Kiesewetter, Dirk and Andreas Lachmund (2004): Wirkungen einer Abgeltungssteuer auf Investitionsentscheidungen und Kapitalstruktur von Unternehmen, Die Betriebswirtschaft, 64 (4): 395-411.

Schneider, Dieter (1969): Korrektur zum Einfluß der Besteuerung auf die Investitionen, Zeitschrift für betriebswirtschaftliche Forschung, 21: 297-325.

Schreiber, Ulrich and Matthias Rogall (200o): Der Einfluss der Reform der Körperschaftsteuer auf Investitionsentscheidungen und den Wert der Gewinnrücklagen von Kapitalgesellschaften, Die Betriebswirtschaft, 60 (6): 721-737.

\section{Biographies}

Jochen Hundsdoerfer is chair of business taxation at the Freie Universität Berlin since 2004. He graduated in business administration (Universität Hamburg). Hundsdoerfer received his doctoral degree in 1996 and postdoctoral lecture qualification and tenure in 2001. His areas of research include tax planning, tax effects on individual behavior, and accounting.

Lutz Kruschwitz is chair of Banking and Finance at the Freie Universität Berlin since 1991. He was born in 1943 in Berlin, Germany, and is a graduate in business administration from the Freie Universität Berlin. Kruschwitz received his doctoral degree in 1970 and his "Habilitation" (postdoctoral lecture qualification) in 1975. His research interests include investment and valuation theory in particular. He holds an Honorary Doctorate from the University of Tübingen, Germany, and is serving as Honorary Professor at the University of Vienna, Austria.

Daniela Lorenz is currently research and teaching assistant at the Banking and Finance chair of the Freie Universität Berlin. Her recent research focuses on taxation effects on valuation and investment theory. She was born in 1983 in Berlin and graduated in business administration from the Freie Universität Berlin in 2007. 